$\begin{array}{ll}\text { Volume } & : 7 \\ \text { Nomor } & : 3 \\ \text { Bulan } & : \text { Agustus } \\ \text { Tahun } & : 2021\end{array}$

\title{
Pelestarian Budaya dalam Tari Wali Krama Murwa pada Tradisi Usaba Sambah \\ di Desa Pesedahan Karangasem
}

Putri Ekaresty Haes

Universitas Pendidikan Nasional

Pos-el: ekarestyhaes@undiknas.ac.id

DOI: $10.32884 /$ ideas.v7i3.468

\begin{abstract}
Abstrak
Penelitian ini bertujuan untuk mengetahui pelestarian budaya yang dilakukan oleh masyarakat desa Pesedahan melalui tari wali krama murwa dalam tradisi usaba samba. Metode kualitatif dengan pendekatan etnografi melalui teknik observasi, wawancara dan dokumentasi. Hasil penelitian menjelaskan bahwa tari wali merupakan tarian sakral yang berfungsi sebagai pelaksana upacara yadnya dan wajib ditarikan oleh penduduk asli setempat (krama murwa), tarian ini memiliki tiga bentuk yaitu Tari Pendet Lanang, Tari Pendet Tari Istri, dan Tari Rejang Lilit. Ketiga tarian ini memiliki makna untuk menyenangkan Ida Betara atau Hyang Kuasa (Tuhan) agar dapat memberikan berkah kemakmuran bagi masyarakat setempat.
\end{abstract}

Kata Kunci

tradisi usaba sambah, tarian tradisional, tari wali krama murwa, pelestarian budaya

\begin{abstract}
This study aims to determine the cultural preservation carried out by the Pesedahan village community through the wali krama murwa dance in the usaba samba tradition. Qualitative method with an ethnographic approach through observation, interviews and documentation techniques. The results of the study explain that the wali dance is a sacred dance that functions as an executor of the Yadnya ceremony and must be danced by the local natives (krama murwa), this dance has three forms, namely the Pendet Lanang Dance, the Pendet Istri Dance and the Rejang Lilit Dance. These three dances have a meaning to please Ida Betara or Hyang Power (God) in order to give the blessing of prosperity to the local community.
\end{abstract}

Keywords

usabha sambah tradition, traditional dance, wali krama murwa dance, cultural preservation

\section{Pendahuluan}

Keserasian antara alam, manusia dan kebudayaan yang berlandas kan pada ajaran agama Hindu merupakan aset potensial bagi Bali untuk menarik wisatawan asing. Wisatawan yang datang ke Bali tertarik untuk mempelajari berbagai kesenian antara lain seni lukis, seni ukir, seni gamelan, dan seni tari. Tiap gerak-gerik tarian biasanya ditarikan dengan lemah gemulai serta penjiwaan. Seni tari yang berasal dari Bali merupakan warisan hasil karya cipta leluhur yang diturunkan pada generasi masa sekarang, selain itu tarian juga merupakan hasil kreasi baru yang mengkombinasikan gerakan-gerakan dalam tarian tradisional dengan gerak tarian modern. Seni tari merupakan salah satu produk kebudayaan manusia, seperti diungkap oleh Koentjaraningrat (1974) dalam (Supeno \& Nugraha, 2021) membagi unsur-unsur budaya kedalam tujuan unsur yaitu (1) sistem organisasi kemasyarakatan, (2) sistem keagamaan, (3) sistem mata pencaharian, (4) sistem ilmu pengetahuan, (5) teknologi dan peralatan, (6) Bahasa serta (7) kesenian. Seni tari tidak hanya mengajarkan gerakan lebih dari itu seni tari juga mengajarkan arti nilai-nilai kehidupan yang penuh dengan makna simbolik dan filosofis, seperti diungkap oleh (Sedana, 2015) ) bahwa kebanyakan tarian bali memiliki karakteristik, struktur koreografi, nafas budaya, bentuk serta fungsi yang berbeda-beda.

Seni tari yang berkembang di Bali dapat digolongkan kedalam beberapa bagian, seperti diungkap oleh (Yulianti, 2014) bahwa seni tari di Bali dibagi menjadi tiga jenis yaitu tari Bebali, tari balih-balihan dan tari wali. Tari Bebali yaitu tarian yang berfungsi sebagai pengiring upacara, umumnya tarian ini memiliki lakon (ceritera), seperti Gambuh, Wayang Wong, Wayang Sudamala dan lain sebagainya. Tari Balih-Balihan adalah kesenian ini dapat dipentaskan kapan dan di mana saja tanpa ada batasan waktu, tempat serta peristiwa-peristiwa yang terlalu

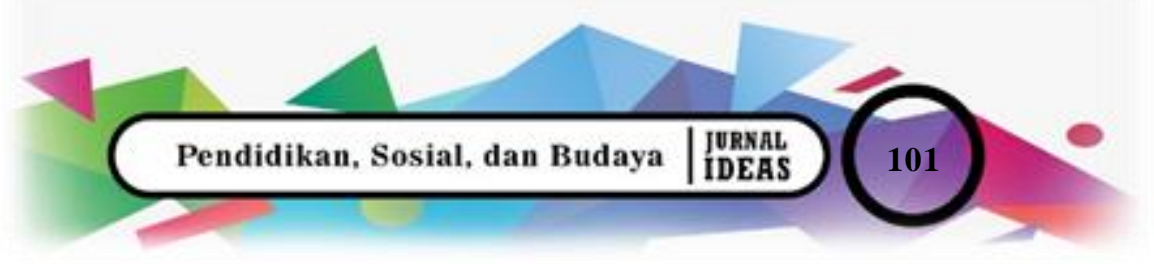


mengikat, seperti Tari Joged, Tari Janger, dan sebaginya. Sedangkan tari wali merupakan tarian sakral yang ditarikan pada saat pelaksanaan upacara ritual di Pura.

Sebelum melaksanaan tarian ritual ini dilakukan proses pasupati terlebih dahulu. Masyarakat Hindu di Bali percaya bahwa semua ciptaan Ida Sang Hyang Widhi memiliki roh, dalam proses pasupati memohon agar Ida Sang Hyang Widhi memberikan roh-Nya dalam tarian wali tersebut. Masyarakat Bali mempercayai adanya kekuatan mistis sang penguasa alam yang dapat memberikan perlindungan dan kemudahan dalam menjalani kehidupan. Oleh karena itu, masyarakat berkewajiban mensyukuri semua yang telah diterima dengan memberikan persembahan berupa sesajen disertai dengan tari-tarian. Tari wali tidak dapat ditarikan oleh sembarang karena berhubungan dengan yadnya. Fungsi tari sebagai sarana upacara merupakan bagian dari tradisi yang sudah ada sejak lama dan merupakan warisan turun-menurun dari nenek moyang.

Pementasan tari wali dilakukan pada pelaksanaan yadnya yang memiliki kendali dalam suatu ritual keagamaan Hindu. Swastika (2010) menyatakan bahwa dalam ajaran agama Hindu "yadnya" adalah sebuah korban suci yang tulus iklhas, yang ditujukan kepada Tuhan Yang Maha Esa/Hyang Widhi Wasa (Dewa Yadnya), manusia atau sesama (ManusiaYadnya), para bhuta atau roh-roh halus (Bhuta Yadnya), para Rsi atau pendeta (RsiYadnya), dan para roh leluhur (Pitra Yadnya). Kelima jenis "yadnya" diatas dikenal dengan istilah "Panca Yadnya", yaitu lima korban suci yang ditunjukan ke hadapan Tuhan Yang Maha Esa atau Ida Sang Hyang Widhi. Lebih lanjut Hadi (dalam Putri, 2013) menyatakan bahwa kehadiran tari di dalam upacara ritual merupakan pengalaman emosi keagamaan berfungsi sebagai sarana pengungkapan kepercayaan dan keyakinan. Salah satu tarian wali yang sampai sekarang masih ditampilkan dalam upacara yadnya terdapat di Desa Pesedahan.

Desa Pesedahan merupakan desa di Kecamatan Manggis, Kabupaten Karangasem. Desa ini masih memegang budaya dan tradisi yang ada secara turun-menurun. Desa Pesedahan memiliki beberapa tarian yang biasa ditampilkan pada upacara ritual, seperti tari rejang lilit, tari pendet istri, dan tari pendet lanang. Tariantarian ini merupakan tari sakral untuk menyambut turunnya dewa-dewi ke bumi. Tarian ini memiliki ciri khas gerakan yang indah, serta mudah diikuti. Selain itu, ketiga tarian tersebut ditarikan mulai anak-anak hingga orang dewasa, laki-laki maupun perempuan yang belum menikah dan sudah mengalami pubertas. Tarian sakral Desa Pesedahan ini tidak sembarang orang yang menarikannya. Ketiga tarian ini ditarikan oleh penduduk asli setempat desa atau disebut "krama murwa" yang dibelakangnya diikuti oleh para pengayah lainnya yang dinamakan tari wali krama murwa. Tari wali krama murwa ditarikan pada rangkaian usaba sambah di Desa Pesedahan yang dilaksanakan pada purnama sasih kelima menurut kalender Bali.

Tradisi usaba sambah merupakan salah satu tradisi keagamaan terbesar yang dirayakan setahun sekali selama sebulan penuh, yaitu pada bulan kelima kalender masehi, yaitu sekitar bulan Juni dan Juli. Dalam kamus Bahasa Bali Indonesia seperti ditulis oleh Dasih (2018), kata "usabha" berasal dari bahasa Jawa Kuno yang mengandung arti perayaan, pesta, atau perjamuan sehingga terkait dengan upacara keagamaan. Kata usabha dapat diartikan sebagai suatu perayaan atau pesta perjamuan ke hadapan Tuhan Yang Maha Esa dalam bentuk persembahan berupa berbagai hasil bumi. Persembahan ini merupakan ungkapan rasa terima kasih dan rasa syukur ke hadapan Tuhan Yang Maha Esa atas segala ciptaan-Nya di alam semesta. Zoetmulder (dalam Dasih, 2018) mengatakan bahwa kata "sambah" dalam kamus Jawa Kuno Indonesia berasal dari kata di mana se artinya satu dan embah artinya perayaan sehingga kata sambah mengandung arti sembah atau memuja.

Kajian tentang tarian pada tradisi usaba sambah telah banyak dilakukan. Savitri dkk., (2018) yang menjelaskan mengenai tari sakral tugleng-tugleng dalam upacara ngusaba sambah di Desa Pakraman Kastala dalam perspektif Hindu. Dalam kajian tersebut terungkap bahwa fungsi pelaksanaan tari sakral tugleng-tugleng bagi masyarakat Desa Pakraman Kastala secara umum adalah sebagai wujud Sraddha Bhakti dan rasa syukur masyarakat setempat kepada Tuhan. Selain itu, tarian ini juga sebagai wujud penetralisasi dan penjaga keseimbangan alam semesta dan keharmonisan kehidupan masyarakat.

Lain halnya dengan kajian bentuk dan fungsi Sang Hyang Sambah dalam ngusabha sambah di Desa Pakraman Pesedahan yang dilakukan oleh Suadnyana (2018). Dalam kajian ini terungkap bahwa fungsi dari Sang Hyang Sambah memiliki beberapa fungsi, yaitu fungsi religius, fungsi kesuburan, fungsi keselamatan, sedangkan makna dari Sang Hyang Sambah dalam ngusabha sambah di Desa Pakraman Pesedahan antara lain makna takwa, makna etika, makna estetika, dan makna kebersamaan. Kajian yang dilakukan oleh Subamia dkk., (2021) mengungkapkan tentang perang pandan yang merupakan salah satu upacara penting dan wajib dilaksanakan pada tradisi usaba samba oleh masyarakat Desa Pengringsingan sebagai bentuk rasa syukur kepada 


$\begin{array}{ll}\text { Volume } & : 7 \\ \text { Nomor } & : 3 \\ \text { Bulan } & : \text { Agustus } \\ \text { Tahun } & : 2021\end{array}$

Tuhan dalam manifestasi sebagai Desa Indra. Kajian lain mengenai seni tari diungkap oleh Alkaf (2013) tentang tari sebagai gejala kebudayaan: studi tentang eksistensi tari rakyat di Boyolali, dalam simpulan penelitiannya terungkap bahwa keberadaan sebuah tarian akan selalu sejalan dengan lingkungan sosial, budaya, ekonomi, bahkan kehidupan politik yang ada pada suatu daerah.

Tradisi dalam kamus antropologi menurut Ariyanto dan Sinegar (1985, dalam Saidita dkk., 2013) adalah kebiasaan yang bersifat magis religius dari kehidupan penduduk asli yang meliputi nilai budaya, norma-norma, hukum dan aturan-aturan sehingga dapat dikatakan bahwa tradisi merupakan pewarisan atas nilai budaya, norma, kaidah dan kebiasaan yang ada pada suatu daerah, yang sampai sekarang masih dijaga eksistensinya. Tujuan dari kajian ini adalah untuk mengetahui bentuk dari pelestarian budaya yang diakukan oleh masyarakat desa Pesedahan dalam menjaga eksistensi dari tradisi Usaba Samba melalui tarian wali krama murwa dalam ketiga jenis tarian, yaitu tari rejang Lilit, tari pendet lanang dan tari pendet istri.

\section{Metode}

Pendekatan etnografi dalam penelitian kualitatif merupakan salah satu pendekatan yang mana peneliti menghabiskan waktu yang cukup lama tinggal bersama dan mengamati budaya masyarakat. Oleh karena itu, peneliti akan langsung mengikuti keseharian dari masyarakat tersebut. Brewer (2000, dalam Morrisan, 2019) mengataan bahwa metode pengumpulan data pada riset etnografi dimaksudkan untuk menggambarkan makna sosial dan aktivitas normal dari suatu masyarakat dalam lingkungan yang mereka alami. Lebih lanjut Brewer (2000, Morrisan, 2019) juga mengungkapkan bahwa pengumpulan data dapat dilakukan melalui observasi partisipan, catatan lapangan, wawancara, dan survei. Sumber data yang dipergunakan adalah sumber data primer dan sekunder, dengan menggunakan teknik purposive sampling dalam menentukan informan penelitian. Keabsahan data dalam penelitian ini menggunakan trianggulasi data. Sugiyono (2018) menyatakan bahwa triangalusi dalam pengujian kredibilitas ini diartikan sebagai pengecekan data dari berbagai sumber dengan berbagai cara dan berbagai waktu. Dengan demikian, teknik keabsahan data dalam penelitian ini mempergunakan triangulasi sumber, triangulasi teknik pengumpulan dat dan triangulasi waktu.

\section{Hasil dan Pembahasan}

Hasil

Sejarah Desa Pesedahan diambil dari prasasti yang terdapat pada Kembal Desa Pekraman Pesedahan. Wilayah Desa Pesedahan Kecamatan Manggis Kabupaten Karangasem berada di bagian tengah kaki bukit tapal kuda bagian timur yang disebut Bukit Tenganan. Gugusan bukit yang hijau lestari membentang melingkar membentuk tapal kuda, meliputi sejumlah desa seperti Sibetan, Macang, Ngis, Tenganan Pegrisingan, Tenganan Dauh Tukad, Pesedahan, Nyuhtebel, Sengkidu, dan Bugbug. Desa Pesedahan yang tepat berada di lembah Bukit Tenganan memiliki batas-batas wilayah, yaitu di sebelah utara dibatasi oleh Desa Tenganan Pegringsingan, di sebelah barat dibatasi oleh Desa Tenganan Dauh Tukad, di sebelah selatan dibatasi oleh Desa Nyuhtebel. dan di sebelah timur dibatasi oleh Bukit Tenganan.

Keberadaan tari wali krama murwa di Desa Pesedahan diawali dengan keberadaan Pura Petilahan, yaitu sebuah pura tempat berstana Ida Bhatara Ayu Batur, yaitu dewi kemakmuran. Pura ini dibangun untuk memohon kemakmuran serta keberlangsungan pembangunan desa. Penuturan salah satu Informan menyatakan bahwa dulu setelah mapamahayu di Pura Rambut Petung dan Kahyangan Desa, I Gusti Ngurah Tenganan memimpin jalannya perekonomian di Prebumian Pesedahan. Dahulu luas wilayah yang dipimpinnya hingga ke Desa Ujung hingga di ujung timur Kabupaten Karangasem. Segala aktivitas perekonomian seperti pasar di masing-masing desa dikenakan pajak atau peti yang dikumpulkan di Desa Pesedahan, tepatnya di Pura Petilahan. Pajak tersebut dikelola oleh Krama Desa Murwa untuk mengucap syukur atas segala yang dianugrahkan, maka dibangunlah Pura Petilahan yang di-sungsung oleh Krama Desa Murwa keturunan dari I Gusti Ngurah Tenganan dan Pan Arya, Pan Kerdi, Pan Trayu, dan Pan Sambat. Dalam melaksanakan upacara maupun piodalan di Pura Petilahan, tokoh masyarakat setempat mendapat pawisik untuk melaksanakan beberapa tarian sakral, yaitu tari pendet lanang, tari pendet istri, dan tari rejang lilit yang ditarikan oleh anak-anak hingga dahaa teruna maupun teruni. Seiring berjalannya waktu, Ida Bhatara Ayu Batur yang berstana di Pura Petilahan juga berstana di Pura

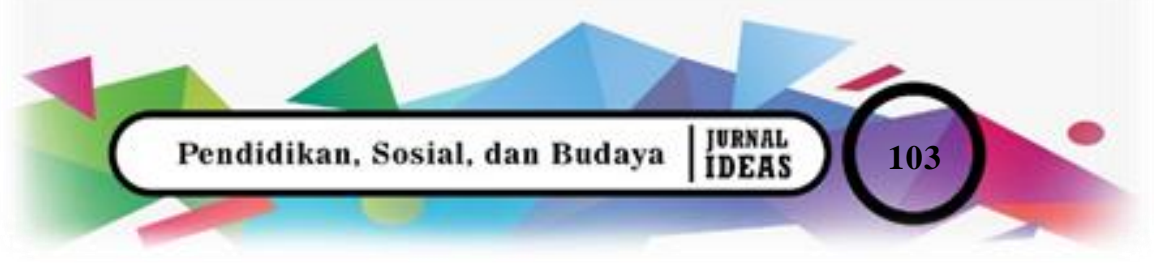


Puseh serta seluruh Ida Bhatara Kahyangan Desa karena diberikan pengodal, maka seluruh tarian dibawa ke Pura Puseh. Ketika tradisi usaba sambah dimulai seluruh Ida Bhatara Kahyangan desa berstana di Pura Puseh.

Pada pementasan dalam tari tentu adanya sarana yang wajib dibawa pada pementasan, khususnya pada tari sakral. Tari sakral memiliki sarana khusus untuk menampilkan ciri khas pada tarian atau sebagai pelengkap upacara kegamaan berlangsung. Tari pendet lanang dan tari pendet istri membawa sarana klungah atau kelapa muda yang dilubangi, tetapi penutupnya tidak dilepas, serta dilengkapi dengan canang dan bokor atau tempat untuk membawanya. Canang rawis terbuat dari daun kelapa yang sering disebut busung yang dijarit di dalamnya dilengkapi dengan daun kayu, porosan (daun sirih yang diisi dengan kapur lalu dilipat dengan busung), serta dilengkapi dengan bunga dan rampe (yang berasal dari daun pandan yang disisir memanjang). Sanganan terdiri dari pisang, buah apel, buah salak, jajan khas Bali seperti jajan merah putih, jajan uli (terbuat dari ketan dan kelapa) merah putih, jajan gina (terbuat dari ketan dikuskus dan digoreng serta dijemur di bawah terik matahari), kambang-kambang (tepung beras diremas dan diisi air panas) dan canang reta atau canang gempuk. Sedangkan untuk tari rejang lilit hanya dibagian akhirnya setelah persembahyangan mendapatkan "ajengan" yang terdiri dari tumpeng setengah, taluh abungkul, dan urab putih kuning.

Tari wali krama murwa yang dimiliki oleh Desa Pesedahan terdiri dari tari pendet lanang, tari pendet istri dan tari rejang lilit. Tari pendet lanang merupakan tari yang ditarikan oleh sekaa teruna yang sudah mengalami puber dan belum menikah. Tari pendet istri juga ditarikan oleh dahaa teruni yang sudah mengalami puber dan belum menikah. Tari pendet lanang dan tari pendet istri ditarikan oleh masyarakat asli setempat Desa Pesedahan. Untuk penari tari rejang lilit adalah anak-anak yang baru bisa berjalan hingga belum mengalami menstruasi, dipilihnya anak-anak dikarenakan masih suci. Tarian ini tidak memiliki latihan khusus hanya mengikuti saja.

Tari wali krama murwa Desa Pesedahan memiliki tempat dan waktu pementasan khusus dilaksanakan pada saat upacara keagamaan yang telah disucikan sebagai tempat sakral pementas an tarian tersebut. Tari pendet lanang dan tari pendet istri dipentaskan di Pura Puseh saat upacara usaba sambah yang tempatnya khusus dipentaskan pada saat penyujukan, pebarisan dan penyuud atau pengusan. Tari Pendet istri dan tari pendet lanang juga ditarikan pada bagian jaba tengah atau madya mandala di pura, dikarenakan tari pendet lanang dan tari pendet istri sebagai tarian membawa persembahan seperti klungah, canang rawis dan sanganan, sedangkan tari rejang lilit ditarikan pada usaba sambah di pura puseh pada paci sambah, penyujukan, pebarisan, penyuud atau pengusan. Tari rejang lilit ini ditarikan pada Jeroan Pura atau Utama Pura dikarenakan tari rejang ini akan mengelilingi seluruh area pura atau murwa daksina sebanyak tiga kali.

Pakaian yang dipergunakan oleh ketiga tarian tersebut memiliki arti tersendiri, seperti diungkap o leh Jero Bendesa Adat pada tabel 1 di bawah ini.

Tabel 1

Busana Adat Ketiga Tarian Wali Krama Murwa

\begin{tabular}{|c|c|c|}
\hline Jenis Tarian & Busana Adat & Keterangan \\
\hline Tari pendet lanang & & $\begin{array}{l}\text { 1. Udeng (mejenggeran) menciptakan kesan kejernihan pikiran serta agar } \\
\text { pemakainya berpikir lurus fokus dalam persembahy angan. } \\
\text { 2. Saput digunakan sebatas dada tujuannya sebagai penghadang musuh } \\
\text { dari luar sebenarnya utamnya menutupi nafsu. } \\
\text { 3. Kamen digunakan sebatas pusar yang melingkar dari kiri ke arah } \\
\text { kanan karena kelak laki-laki menjadi penaggung jawab dharma } \\
\text { tertinggi dan kamen melancing menyentuh tanah sebagai } \\
\text { penghormatan pada ibu pertiwi. }\end{array}$ \\
\hline Tari pendet istri & & $\begin{array}{l}\text { 1. Rambut pada tari pendet istri disanggul dibentuk sesuai keinginan } \\
\text { tidak boleh terurai yang merupakan sebagai etika dalam memasuki } \\
\text { area Pura dan dihiasi dengan bunga emas agar terlihat cantik. } \\
\text { 2. Kemben (kain) merupakan kain rembang atau prada yang digunakan } \\
\text { sebatas dada yang disimbolkan hendaknya perempuan menjaga } \\
\text { kesehatan rahimnya agar kelak mendapatkan keturunan yang suputra. } \\
\text { 3. Selendang dilipat dari arah kiri dan dibawa ke belakang membiarkan- } \\
\text { nya menjuntai panjang sebelah sebagai makna pengendalian hawa } \\
\text { nafsu. } \\
\text { 4. Kamen pada tarian pendet istri lipatan kamennyamelingkar dari arah } \\
\text { kanan ke kiri, hal ini bermakna perempuan sebagai sakti bertugas } \\
\text { menjaga laki-laki agar tidak melenceng dari ajaran dharma. }\end{array}$ \\
\hline
\end{tabular}




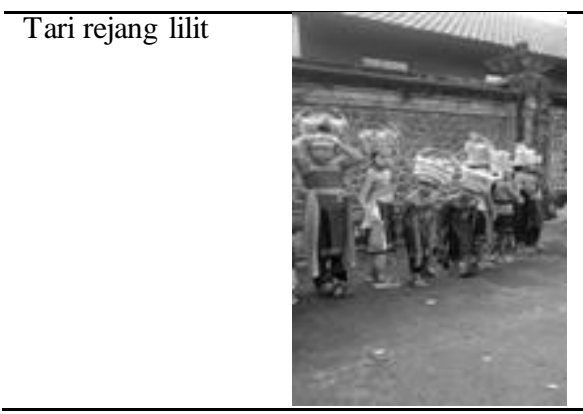

1. Gelungan yang digunakan menyimbolkan kesiapan penari untuk ngayah serta kesucian penari. Pada gelungan tersebut dihiasi dengan bunga warna-warni, seperti jepun merah putih, bunga mawar, bunga gumitir dan lainnya serta ditambah bunga emas melambangkan wangi dan segarnya pada saat menarikan rejang.

2. Penari menggunakan saput rejang khas Desa Pesedahan merupakan simbol identitas adalah keturunan dari krama Desa Pesedahan.

\section{Pembahasan}

Hadi (dalam Djamalu, 2014) bahwa Seni Tari sebagai ekspresi manusia yang bersifat estetis merupakan bagian tak terpisahkan dari kehidupan manusia dalam masyarakat yang penuh makna (meaning). Tari wali krama murwa merupakan tarian bersifat sakral yang dilaksanakan sebelum persembahyangan dimulai. Tarian ini merupakan karya seni yang telah ada sejak dulu. Maka dari itu, tarian ini memiliki makna sebagai Tari persembahan wujud terima kasih atas kerahayuan dan kemakmuran yang diberikan kepada masyarakat Desa Pesedahan. Gerakan penari tari pendet istri memiliki makna ungkapan penuh kelembutan nan anggun yang terlihat pada agamenan penari dan melintang tangannya. Tari pendet lanang memiliki gerakan ageman, nayog, dan tanjek ungkapannya sebagai keperkasaan dan kewibawaan laki-laki yang penuh semangat jiwa, sedangkan tari rejang lilit pada gerakannya sebagai ungkapan menyambut kedatangan Ida Bhatara pada rangkaian upacara.

Di lingkungan masyarakat yang masih kental adat istiadatnya, seni tari memiliki fungsi upacara. Fungsi tari sebagai sarana upacara merupakan bagian dari tradisi yang sudah ada sejak lama dan merupakan warisan turun-menurun dari nenek moyang. Tari wali krama murwa yang merupakan tarian sakral yang ditarikan oleh pemuda-pemudi sebagai regenerasi agar tidak melupakan persembahayangn dan wujud bakti kepada Ida Bhatara/Tuhan Yang Maha Esa, serta mengenalkan kepada penari anak-anak perempuan seperti inilah pementasannya. Serangkaian usaba sambah tari wali krama murwa selalu dipentaskan sebagai pelengkap ataupun pengiring upacara. Supartha (dalam Djamalu, 2014) mengatakan bahwa tari upacara yang pada umumnya bersifat sakral dan magis disebut tari wali. Dalam upacara-upacara pada suku-suku bangsa premitif sebuah tarian yang memegang peranan penting.

\section{Simpulan}

Tradisi usaba sambah berasal dari Desa Pesedahan Kecamatan Manggis Kabupaten Karangasem. Rangkaian usaba sambah ini menandakan ucapan syukur ke hadapan Tuhan Yang Maha Esa atas kerahayuan dan kemakmuran. Ucapan syukur tersebut dilakukan melalui gerakan tarian. Tari wali krama murwa yang terdiri dari tari pendet lanang, tari pendet istri dan tari rejang lilit merupakan gerak tari persembahan pada tradisi usaba sambah sebagai ucapan terima kasih ke hadapan Tuhan Yang Maha Esa atas kesejahteraan yang diberikan.

\section{Daftar Rujukan}

Alkaf, M. (2013). Tari Sebagai Gejala Kebudayaan: Studi Tentang Eksistensi Tari Rakyat Di Boyolali. KOMUNITAS: International Journal of Indonesian Society and Culture, 4(2), 125-138. https://doi.org/10.15294/komunitas.v4i2.2401

Dasih, I. G. A. R. P. (2018). Komunikasi Simbolik dalam Tari Pendet Lanang pada Usabha Sambah di Desa Pakraman Pesedahan Kecamatan Manggis Kabupaten Karangasem. Widya Duta: Jurnal Ilmiah Ilmu Agama Dan Ilmu Sosial Budaya, 13(1), 1. https://doi.org/10.25078/wd.v13i1.429

Djamalu, W. (2014). Tari Maengket: Maowey Kamberu di Desa Kaaruyan Kecamatab Mananggu Kabupaten Boalemo [UNIVERSITAS NEGERI GORONTALO]. https://repository.ung.ac.id/skripsi/show/341408039/bentuk-pertunjukantari-maengket-maowey-kamberu-di-desa-kaaruy an-kecamat an-manan ggu-kabupaten-boalemo.html

Ersa Mega Reta Putri. (2013). Fungsi dan Bentuk Penyajian Tari Sambut Dalam Upacara Penyambutan Tamu di Muara Enim, Sumatra Selatan [UNIVERSITAS NEGERI YOGYAKARTA]. In UNIVERSITAS NEGERI YOGYAKARTA. http://eprints.uny .ac.id/27746/1/Ersa Mega Reta Putri 09209241034.pdf

Morrisan. (2019). Riset Kualitatif (Edisi Pert). Prenanda Media.

Saidita, W., Azwar, A. J., \& Yani, A. (2013). Kepercayaan Masyarakat Terhadap Ritual Mitoni Ditinjau Dari Aqidah Islam (Studi di Desa Rejosari Kecamatan Muara Sugihan Kabupaten Banyuasin). Skripsi Universitas Islam Negeri Raden Fatah, 53(9), 1689-1699.

Savitri, N. W. N., Mardika, I. K., \& Luwih, I. M. (2018). Tari Sakral Tugleng-tugleng dalam Upacara Ngusaba Sambah di Desa Pakraman Kastala Kecamatan Bebandem Kabupaten Karangasem (Perspektif Pendidikan Agama Hindu). Jurnal

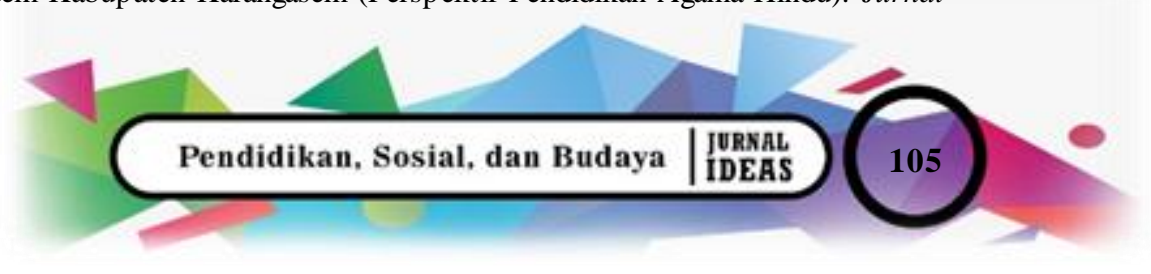




\begin{tabular}{c|ll} 
EE-ISSH: 2656-940X & Volume & $: 7$ \\
Nomor & $: 3$ \\
P-ISSH: 2442-367K & Bulan & $:$ Agustus \\
TRL: jurnal.jdeaspublishing.co.id & Tahun & $: 2021$
\end{tabular}

Penelitian Agama Hindu, 2(1), 96-103.

Sedana, I. G. A. (2015). Busana Tari Bali Dalam Fashion Photography [INSTITUT SENI INDONESIA YOGYAKARTA]. https://doi.org/ttps://doi.org/10.24821/srs.v0i0.832

Suadnyana, I. B. P. E. (2018). Sang Hyang Sambah Dalam Ngusabha Sambah Di Desa Parkaman Pesedahan Manggis Karangsem (Kajian Bentuk, Fungsi dan Makna). 9(1), 87-96.

Subamia, I. N., Suastika, I. M., \& Lingih, I. N. (2021). Mytologi Representation Dewa Indra in Pandage War at Usaba Waste Ceremony in the Tenganan Traditional Village Pegringsingan Manggis, Karangasem, Bali (Social Theological Perspective). Sociological Jurisprudence Journal, 4(1), 68-74. https://doi.org/10.22225/scj.4.1.2646.68-74

Sugiyono. (2018). Metode Penelitian Kuantitatif, Kualitatif, $R$ dan D. Alfabeta.

Supeno, M. Y., \& Nugraha, A. (2021). Aspek Sains dan Budaya Instrumen Cetik dalam Tinjauan Etno Organologi Akustik. Ideas: Jurnal Pendidikan, Sosial, Dan Budaya, 7(2), 125. https://doi.org/10.32884/ideas.v7i2.362

Yulianti, N. K. D. (2014). Eksistensi Tari Bali dan Jawa dalam Bahasa Indonesia dan Inggris. Segara Widya, 2 No. 1, 249 259. 